\title{
Fermented Herbal Decoction Selectively Targeting Human Cancer Cell Line and Human Pathogenic Microorganism
}

\author{
Nobuo Yamaguchi ${ }^{*}$, Nurmuhammat Amat ${ }^{2}$, Kazuhiro Okamoto ${ }^{3}$, Tsugiya Murayama4 \\ ${ }^{1}$ Ishikawa Natural Medicinal Product Research Center, Kawakawa, Japan \\ ${ }^{2}$ Traditional Uyghur Medicine Institute, Xingjian Medical University, Urumqi, China \\ ${ }^{3}$ Department of Rehabilitation, Kanazawa Medical University, Uchinada, Japan \\ ${ }^{4}$ Department of Microbiology and Immunology, Faculty of Pharmaceutical Sciences, Hokuriku University, Kanazawa, Japan \\ Email: *serumaya @kanazawa-med.ac.jp
}

How to cite this paper: Yamaguchi, N., Amat, N., Okamoto, K. and Murayama, T. (2018) Fermented Herbal Decoction Selectively Targeting Human Cancer Cell Line and Human Pathogenic Microorganism. Open Journal of Rheumatology and Autoimmune Diseases, 8, 17-33. https://doi.org/10.4236/ojra.2018.81002

Received: November 21, 2017

Accepted: January 28, 2018

Published: February 2, 2018

Copyright $(9) 2018$ by authors and Scientific Research Publishing Inc. This work is licensed under the Creative Commons Attribution International License (CC BY 4.0).

http://creativecommons.org/licenses/by/4.0/

\section{(c) (i) Open Access}

\begin{abstract}
Introduction: Prolonged immuno-suppressed status promised to induce internal growth of malignant cell and infectious agent, yet, only a small part of affected individuals seek medical attention or berried by commercially over-flowed fake information. Several studies have described complementary and alternative medicine as effective strategies for improving anti-infectious agent including malignant cell. The purpose of this study was to investigate the effect of a fermented herbal decoction (FHD) both in vitro and in vivo to malignant cells and microorganism by regulating leukocyte subset proportioning FHD as dietary material. Methods: In this approach of alternative study, selective anti-cancer effect by fermented decoction was tried to show first in vitro system both, cancer cell and virus strain. The fermented herbal decoction consisting of 80 sorts of herbs and fruits. The selective toxicity was set up and then for immunological factors in animal and human. The most important factor is to reduce side effect for a normal cell. Results: First, FHD was proved as safe by animal test. FHD regulated also the proportion of granulocyte and lymphocyte ratio both animal and human. In vitro culture showed selective toxicity by FHD against human melanoma and leukemia cell line but reduced toxicity was showed by normal cell line. As for the anti-virus activity, anti-virus effect was tested on the feeder layer of human fibroblast cell, after 9 days of culture. Second, FHD inhibits colon cancer growth in 3-methylholanthrene induced cancer in rat. Conclusion: The present results suggest that our fermented herbal decoction showed selective anti-cancer activities and anti-virus activities, together with the regulative effect on the immune system.
\end{abstract}




\section{Keywords}

Fermented Herbal Decoction, Human Malignant Cell Line, Human Normal

Cell Line, Anti-Virus Activity, 3-Methylholanthrene, Experimental Colon

Cancer, In Vitro, In Vivo Anti-Cancer Trial

\section{Introduction}

Acquired immune deficient status refers to persistent or repeated episodes of clinically unexplainable fatigue that occur for a life related style. Prolonged fatigue is a common condition in the general population, while the prevalence of prolonged fatigue varies across communities and primary care settings, it is highly prevalent among working populations and young, adults and senile [1]-[11]. A Dutch Maastricht cohort study reported that $21.9 \%$ of working adults had prolonged fatigue. Another study indicated that $23.1 \%$ of patients visiting a primary medical institution showed prolonged fatigue, $50 \%$ of whom were between 30 - 49 years of age. Consistent with this finding, several studies have noted a high prevalence of chronic fatigue syndrome in adults [12] [13]. Fatigue not only affects daily life and social as well as occupational functions but is also detrimental to health in the long term, implicated as a cause of immune-deficient status, cancer and decreased QOL [9] [10]. Thus, prolonged fatigue is a condition that requires early prophylactic intervention and effective treatment by the instances reported [14]-[27]. So preventive medicine by so called CAM is required in this industrial world. There were many findings that reported in all over the world about anti-cancer agent. However, almost all the materials showed the cell toxicity against normal cell as well as cancer cell. In this report, the natural product had been known for anti-fatigue agent but recently reported the anti-cancer effect elsewhere [9] [10]. The trial had been made to clarify the FHD both in vitro and in vivo system. Numerous publications have focused on the mechanisms of pancreatic cancer development and progression associated with exposure to carcinogenic material, 3-methylecoranthrene famous carcinogen for colon cancer, and other tobacco-related carcinogens [5] [9] [10]. An immunocyte, especially NK cell has been identified as an important regulator of cell proliferation, apoptosis, migration, and angiogenesis in the most common epithelial human cancers [9], including cancer of the lung [28] [29], colon [30] [31], breast [32], oral cavity [33], stomach [34] [35], and pancreas [36]. It was initially thought that cellular responses after treatment of cancer cells with carcinogen were caused by intracellular signaling pathways activated immediately downstream of carcinogenesis [32]. However, emerging research suggests that most of these reported signaling events are in fact indirect responses caused by the carcinogen-mediated synthesis and release of neurotransmitters by cancer cells and the epithelia from which they arise [14]. In conventional western medicine, fatigue is treated with pharmacotherapy such as antidepressants or corti- 
costeroids in order to mitigate or relieve symptoms that accompany fatigue; however, these medications are associated with various side effect. Additionally, despite the fact that a considerable proportion of the population exhibited prolonged fatigue [25]. Accordingly, many people who experience fatigue have turned to complementary and alternative medicine (CAM), and it was reported that a lot of people with fatigue symptoms use CAM, and the people with prolonged fatigue in the United States are attracted by CAM [26]. Among various CAM methods, fermented herbal decoctions; FHD have received substantial attention based on the fact that they are readily accessible and are generally perceived as safe. In fact, a previous clinical trial reported that fermented herbal decoctions significantly activated for complement system [37] [38] [39] [26] [27] [28]. So, this study to date has evaluated a fermented herbal decoction formulated in accordance with Traditional Alternative Medicine. The aim of this study was to conduct a clarification of the oral approach for regulate host immune system and against the parasite even in internal malignant cell itself.

\section{Material and Methods}

\subsection{Animal Test for Material Safety Confirmation}

Ten female eight-week-old ddY mice, were severed for the acute oral toxicity observation. The test systems were carried out according to Ethics of the Organization for Economic Co-operation and Development (OECD) Test Guideline 401. The mice were kept at $24^{\circ} \mathrm{C} \pm 1{ }^{\circ} \mathrm{C}, 50 \%$ relative humidity in a SPF conditioned system.

\subsection{Characterization of FHD in Vivo}

Harmonization had been issued, (ICH)/WHO Good Clinical Practice standards (GCP) including certification by an external audit. The trial protocol has been approved by according to the Research Ethical Committee of Kanazawa Medical University. The assessments including a total number of leukocytes was ordered to count with blood chemical test for the medical diagnosis of public institution (Ishikawa Preventive Medicine Association, Ishikawa, Japan). In the differential counting, 200 cells were counted on a May-Grünewald-Gimsa stained slide, and percentages of lymphocytes and granulocytes were determined.

\subsection{Study Design of Leukocyte and Leukocyte Subsets Assessment for Estimating FHD}

We selected 30 healthy volunteers (mean age, $32.3 \pm 7.8$ years) and informed consented according to The Ethics Committee of Kanazawa Medical University. In addition, the experimental group was further divided into two groups according to the dosage variation. The peripheral blood obtained from the subjects by blood collection tube containing an anticoagulant EDTA-2K. (Becton Dickinson) as a secondary antibody and were incubated for 90 minutes at $4^{\circ} \mathrm{C}$. After washing with PBS, +FCS, the grass adherent cells were added after washing with 
PBS and served for the processing described in Section 2.5 After confirming safety test in mice [40] [41], human volunteers $(\mathrm{n}=30)$ divided in to two groups that the grouping criteria by Abo et al., lymphocyte rich group and granulocyte rich group [40] [41]. FHD were administered for one month and estimated blood cell before and after the trial. The constitution/condition dependent regulation in both in L rich type and G-rich type by administrating FHD, We reported that according to the lymphocyte subset content, lymphocyte rich type showed over $40 \%$ on the other hand granulocyte rich type show over $60 \%$ of granulocyte. Each type exhibited different character even in the same age, sexuality and each ager of individual. In the figure, within the same age and the sex, even in mankind can sorts out as G-rich type (granulocyte-rich) an/or L-rich type [29] [30] [31].

\subsection{Regulation of Leukocyte and Leukocyte Subsets for Characterizing FHD as Immuno-Regulating Agent}

After confirming safety test for mice [40], human volunteers $(\mathrm{n}=30)$ divided in to two groups that the grouping criteria by Abo et al, lymphocyte rich group and granulocyte rich group [41] [42] [43]. FHD were administered for one month and estimated blood cell before and after the trial. The constitution/condition dependent regulation in both in L rich type and G-rich type by administrating FHD, We reported that according to the lymphocyte subset content, lymphocyte rich type showed over $40 \%$ on the other hand granulocyte. After administrating FHD for one month, Both L-rich and G-rich types regulate for the intermediate value of lymphocyte and granulocyte ratio (Table 1).

\subsection{Experimentally Induced Colon Cancer and FHD Application as CAM Therapy}

Experimentally induced male rat colon cancer were induced by 3-methylholanthrene; ECC (43). The group were divided into three four groups. They were Normal group, ECC, ECC+FHD. FHD were fur their divided according to their doses. Based on previous studies [44], the safety test were reported in the former reports [45].

\subsection{Evaluation of FHD in Vitro}

\subsubsection{Reagents and Virus}

TCDD was purchased from Radian International (Austin, TX 78720-1088, Catalog No. ED-901-B, Solution Lot: 34694-09). The chemical purity of this TCDD was $98 \%$ by chromatographic analysis. A goat anti-AhR polyclonal IgG antibody, N-19, was purchased from Santa Cruz Biotechnology (Santa Cruz, CA 95060, USA). The Towne strain of CMV was used throughout the study, and has been described elsewhere [19]. CMV was propagated in MRC-5 cells, and the clarified supernatant stored in liquid nitrogen until use. Viral infectivity was titrated by plaque assay [32]. Cell culture. MRC-5 [32], and a human hepato-blastoma cell line, HepG2, purchased from the American Type Culture Collection, were cul- 
tured in Dulbecco's modified Eagle's minimal essential medium (DMEM) (Nissui Pharmaceutical, Tokyo) supplemented with $10 \%$ heat-inactivated fetal calf serum (FCS; Z. L. Bocknek Lab., Ont., Canada), L-glutamine $(0.3 \mathrm{mg} / \mathrm{ml})$, gentamicin $(50 \mathrm{mg} / \mathrm{ml})$, and amphotericin B $(2.5 \mathrm{mg} / \mathrm{ml})$. All cell cultures were maintained in a humidified incubator at 37 _C in 5\% $\mathrm{CO}_{2} / 95 \%$ air. Viral production. When MRC-5 cells in 24-well plates (IWAKI Microplate, IWAKI Glass, Funahashi, Japan) reached confluency, the cells were inoculated with CMV at a multiplicity of infection (moi) of 0.1 . After adsorption for $1 \mathrm{~h}$, the cells were added with $1 \mathrm{ml}$ of DMEM medium containing $2 \%$ fetal calf serum in the presence or absence of various concentrations of TCDD for the indicated time intervals. Production of infectious virus was titrated using a plaque assay [46] [47] [48] (Figure 1).

\subsubsection{Human Cell Lines}

An established human cell line were purchase from American Type Culture Collection (ATCC), A normal cell line and tumor cell line were prepared by ATCC and THP-1; Astrocytoma, U373MG; Human glioblastoma astrocytoma, MRC-5 ; Human embryo fibroblast (Normal Cell Line). First, FHD was diluted and prepared $10 \%, 1 \%$ and $0.1 \%$ as final concentration in RPMI-1640 plus FCS. Then each cell line were prepared $5 \times 10^{4}$ cell in each microplate well. The plate were incubated with $5 \%$ of $\mathrm{CO}_{2}+38 \mathrm{c}$ in $\mathrm{CO}_{2}$ incubator. After 24 hrs incubation cultured cell were washed with $1 \mathrm{ml}$ of PBS suspension. Trypan-blue dye $(0.4 \%)$ was mixed to indicate the living cell in the suspension as dye exclusion test.

\subsubsection{Regulation of Leukocyte and Leukocyte Subsets for Estimating FHD Character}

After confirming safety test for mice, human volunteers $(n=30)$ divided in to two groups that the grouping criteria by Abo et al., lymphocyte rich group and granulocyte rich group [14]. FHD were administered for one month and estimated blood cell before and after the trial. The constitution/condition dependent regulation in both in $\mathrm{L}$ rich type and G-rich type by administrating FHD, We reported that according to the lymphocyte subset content, lymphocyte rich type showed over $40 \%$ on the other hand granulocyte. Tis trial had been performed during May, 1st to May $31^{\text {st }}$, including peripheral blood collection.

After administrating FHD for one month, Both L-rich and G-rich types regulate for the intermediate value of lymphocyte and granulocyte ratio (Table 2).

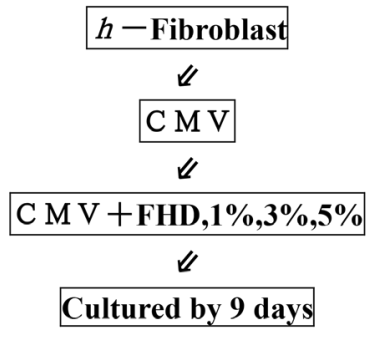

Figure 1. Study diagram $H$-Cytomegaro virus by FHD. 
FHD showed cytotocicity as 5\%, 8\% and 55\% for human nerve cell line U373MG. However decresed cytotoxicity was shown to human normal cell line MEWO, showing tumor specific cytotoxity. This FHD specific toxicity was confirmed another human tumor cell line, leukemia, melanome.

\subsection{Statistical Analysis}

Data were analyzed employing the 2002-2003 SAS Version 9.1 software (SAS Institute Inc. Cary.NC, USA) represented as means \pm standard deviations. The differences between MRY-treated and non-treated control were compared using a one-tailed analysis of variance. A $P$ value $<0.05$ was regarded to be statistically significant.

\section{Results}

\subsection{Background Characteristics of FHD}

\subsubsection{In Vivo Experimental Immuno-Suppressed Mice and FHD Treatment}

Forty individuals were assessed for eligibility and met the inclusion criteria. Twenty participants were randomized to each group. Five participants in the $\mathrm{T}$ group were lost to follow-up (two participants at four weeks and three participants at eight weeks); thus, 30 participants completed the study (Figure 1). The baseline characteristics of participants are summarized in Table 1 . The mean age was $39.9 \pm 2.6$ years in the $\mathrm{T}$ group and $39.3 \pm 6.0$ years in the $\mathrm{C}$ group. The mean fatigue duration was $4.05 \pm 1.23$ months in the $\mathrm{T}$ group and $4.15 \pm 1.18$ months in the $\mathrm{C}$ group. The baseline characteristics were well balanced between the groups with regard to sex, age, body-mass index, drinking, smoking, and disease history $(P>0.05)$ (Table 1$)$. The mean fatigue score at baseline was 20.0 \pm 3.13 in the $\mathrm{T}$ group and $18.9 \pm 4.22$ in the $\mathrm{C}$ group, and secondary outcome measures at baseline including sleep quality, depression, and quality of life were not significantly different between the groups $(P>0.05)$ (Table 1$)$.

\subsubsection{In Vivo Experimental Immuno-Suppressed Mice and FHD Treatment}

In the animal model of immuno-competency reduction, mice were injected with MMC (5 mg/kg) to inhibit the bone marrow. An extract of FHD, which was breezed and dried, was administered orally at a dosage of $1 \mathrm{~g} / \mathrm{kg} /$ day for five consecutive days. In the combined treatment group with FHD + antibiotics, the number of bacteria decreased markedly. Moreover, in the joint treatment group, the blood bacteria number increase 6 hours and 12 hours after treatment and a great number of bacteria lasted after 24 hours. On the other hand, there was no increasing in bacteria count in the treatment group. After introducing MMC, additionally FHD was administered orally for five days. Two days after the last administration, spleen cells were removed, and phagocytic cells and lymphocytes were passively transferred into recipient mice whose bone marrows were inhibited (Figure 2). 
Table 1. Constitution dependent regulation of lymphocyte by FHD.

\begin{tabular}{ccccc}
\hline & \multicolumn{2}{c}{ G type individual } & \multicolumn{2}{c}{ L type individual } \\
\cline { 2 - 5 } CD & \multicolumn{2}{c}{ FHD } & \multicolumn{2}{c}{ FHD } \\
\cline { 2 - 5 } & Before (\%) & After (\%) & Before (\%) & After (\%) \\
\hline CD2 & 6.66 & 76.76 & 60.43 & 77.65 \\
CD4 & 19.54 & 28.44 & 31.43 & 45.67 \\
CD8 & 37.65 & 42.57 & 26.38 & 28.63 \\
CD11 & 73.77 & 72.68 & 63.45 & 69.54 \\
CD14 & 0.03 & 0.06 & 0.06 & 0.07 \\
CD16 & 67.65 & 58.55 & 54.24 & 46.67 \\
CD19 & 8.45 & 8.21 & 8.41 & 7.95 \\
CD56 & 1.57 & 1.88 & 1.78 & 2.87 \\
\hline
\end{tabular}

Constitution dependent regulation of leukocyte by Rice Yeast, Volunteer were divide according to their constitution base on their Lymphocyte Subpopulation expressed as CD positive Cell. The data represented the value obtained 30 days after MRY administration.

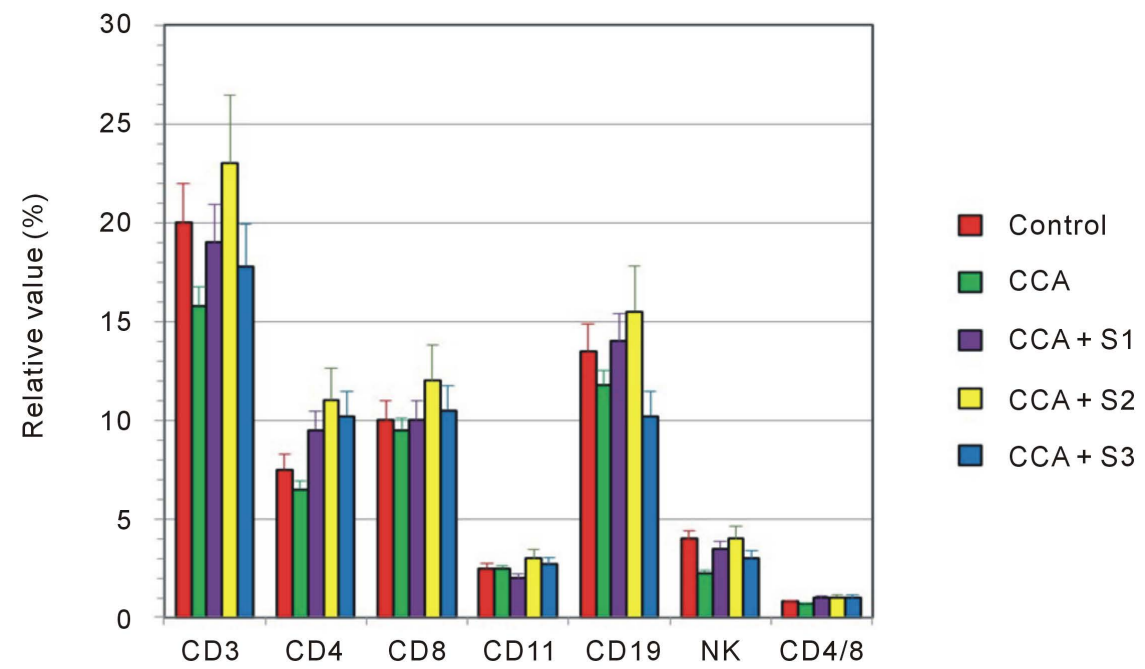

Fifty C57BL/6 mice were divided into five groups. Red group was control. Another four groups were administered cancer chemotherapeutic agent: CCA, Mitomycin-C, $5 \mathrm{mg} / \mathrm{kg}$ each mouse. S1 (violet) group was given $300 \mathrm{mg} / \mathrm{kg}$ of FHD, S2 (yellow) group was given $600 \mathrm{mg} / \mathrm{kg}$ of FHD and S3 (blue) group was $900 \mathrm{mg} / \mathrm{kg}$. Ten days after the experiment, spleen cell were prepared and analyzed by CD positive lymphocyte.

Figure 2. In vivo experimental immuno-suppressed mice and FHD treatment.

\subsubsection{In Vivo Experimental Anti-Tumor System in Immuno-Suppressed Mice and FHD Treatment}

Sixty C57BL/6 mice were divided into two groups. One group was administered FHD $1 \mathrm{~g} / \mathrm{kg}$ for all the course of experiment. Another group was given same dose of FHD before fermentation. All the group were administered 3 methycoranthrene. Each week after the inducer administration, number of Colon cancer foci were macroscopically counted. As shown in Table 2, tumor foci in the intestine were different in the compared groups. 
Table 2. The number of colon cancer foci in surface of colon and effect by FHD.

\begin{tabular}{cccc}
\hline & $\begin{array}{c}\text { FHD group } \\
(\mathrm{n}=30)\end{array}$ & $\begin{array}{c}\text { Control group } \\
(\mathrm{n}=30)\end{array}$ & p-value \\
\hline 0 day & 0 & 0 & -- \\
1 week & 0 & 0 & -- \\
2 week & 0 & $1.6 \pm 0.1$ & 0.473 \\
3 week & 0 & $3.5 \pm 0.3$ & 0.668 \\
4 week & $1.5 \pm 0.3$ & $12.3 \pm 3.3$ & 0.267 \\
\hline
\end{tabular}

Sixty C57BL/6 mice were divided into two groups. One group was administered FHD $1 \mathrm{~g} / \mathrm{kg}$ for all the course of experiment. Another group was given same dose of raw material before fermentation. All the group were administered 3methycoranthrene. Each week after the inducer administration, number of Colon cancer foci were macroscopically counted.

\subsection{In Vitro Experiment for Identifying FHD}

\subsubsection{Cytopathic Effect for Human Pathogenic Virus and Anti-Virus Activities by FHD}

Direct evidence to human pathogenic vires, human cytomegaro virus was mixed with FHD in a different concentration of the decoction.

The culture system were observed through 9 days of the in vitro culture system, shown by photos in Figure three (Figure 3(a) to Figure 3(f)).

The result of anti CMV effect by FHD were Precisely reported in the photo regents under the results in photo.

\subsubsection{Selective Cytotoxic Effect of Human Malignant Cell Line by FHD}

So as to identify the Selective Cytotoxic Effect of Human Malignant Cell Line by FHD, FHD were directory mixed and cultured for 10 days. The human three different cultured cancer cell line were used in this experiment, Human Malignant Melanoma, Human Leukemia Cell Line and Human glioblastoma astrocytoma Cell Line and Normal Cell line.

First, FHD was diluted and prepared $10 \%, 1 \%$ and $0.1 \%$ as final concentration in RPMI-1640 plus FCS. Then each cell line were prepared $5 \times 10^{4}$ cell in each microplate well. The plate were incubated with $\mathrm{CO}_{2}$ incubator. After $24 \mathrm{hrs} \mathrm{in}$ cubation cultured cell were washed with $1 \mathrm{ml}$ of PBS suspension. Trypan-blue dye $(0.4 \%)$ was mixed to indicate the living cell in the suspension as dye exclusion test.

According to the culture test, FHD were showed specific cytotoxicity for either cancer cell line in at least three major cell line (Figure 4(a) to Figure $4(c))$.

\subsection{Safety Assessment}

There was no specified events were found during the study period. In the FHD group, there were no significant mean changes in Biochemical parameter between baseline and post-treatment [49] [50]. 


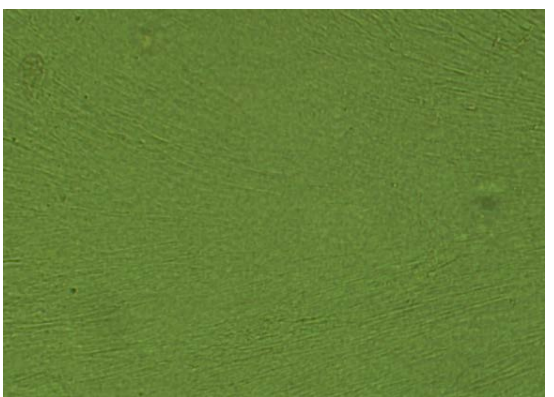

(a)

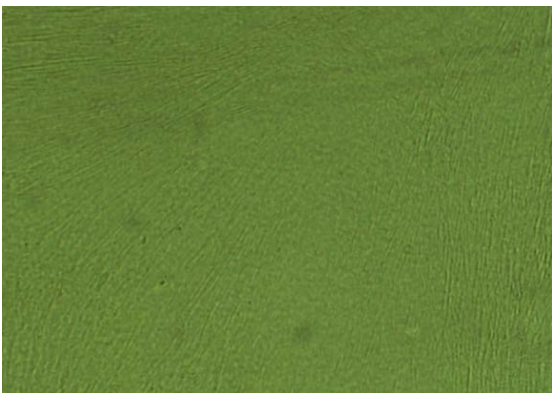

(d)

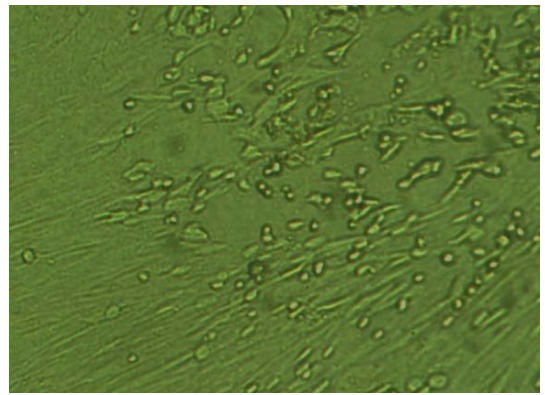

(b)

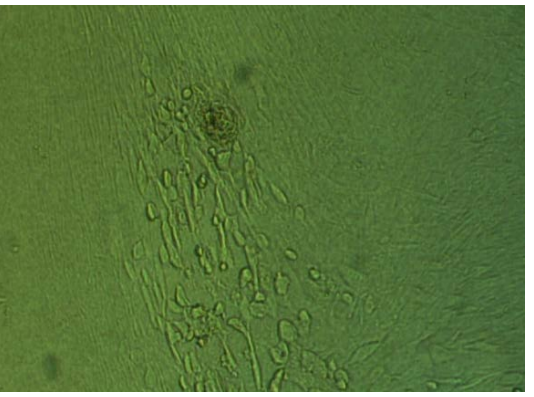

(e)

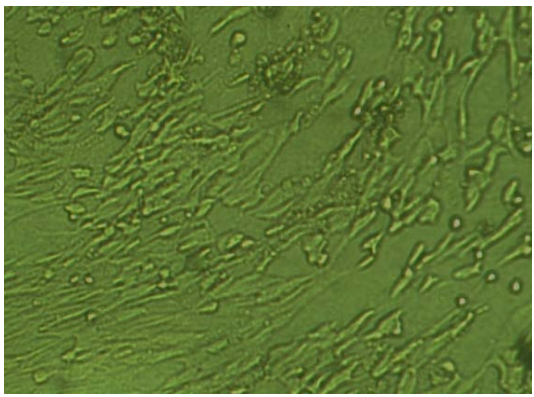

(c)

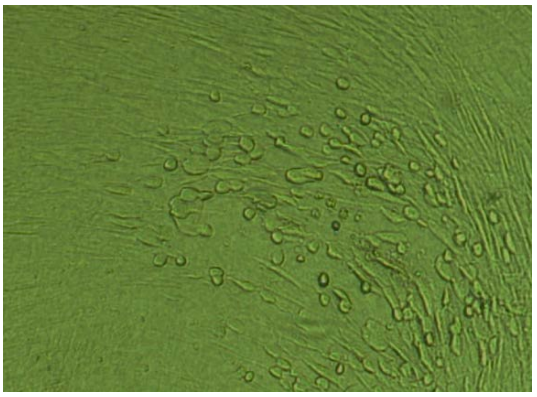

(f)

Photo Legend; (Microscopical Representation of anti-virus effect of HFD by x1 magnification by Digital Camera). (1) Photo of fibroblast layer before infected by HCMV; The layer was prepared for replication of HCMV; (2) Infected layer cell; The fibroblast layer on 9 days after infected by HCMV(PFU1000), indicating degradation of layer cells; (3) Infected layer cell; The fibroblast layer on 9 days after infected by HCMV(PFU2000), indicating severe degradation of layer cells; (4) Infected layer cell $+5 \%$ FHD; The fibroblast layer on 9 days after infected by HCMV(PFU1000)with 5\%of FHD mixture, indicating no degradation of the layer, indicating no degradation of layer cells; (5) Infected layer cell+3\%FHD; The fibroblast layer on 9 days after infected by HCMV(PFU1000)with 5\%of FHD mixture, indicating no degradation of the layer, indicating severe degradation of layer cells; (6) Infected layer cell $+1 \%$ FHD; The fibroblast layer on 9 days after infected by HCMV(PFU1000)with 5\%of FHD mixture, indicating no degradation of the layer, indicating severe degradation of layer cells.

Figure 3. Cytopathic Effect by $h$-CMV and the Effect of HFD in vitro. (a) Huma Fibroblast Cell (HFC); (b) HFC+Human CMV (1000 moi); (c) HFC+Human CMV (2000 moi); (d) HCMV-infected + FHD (5\%); (e) HCMV-infected + FHD (3\%); (f) HCMV-infected + FHD (1\%) + 1\%.

\section{Discussion}

In this study, we compared and analyzed the effects of a fermented herbal decoction regimen on prolonged fatigue in young adults. Our results showed that the FHD had significant reductions in fatigue severity after the fermented herbal decoction intervention, and improved fatigue in the group were significantly different from the control group. Furthermore, improvements in fatigue were maintained simultaneous regulation of leukocyte subset proportion. Four weeks after completion of the intervention, suggesting that the fermented herbal decoction used in this study produced lasting beneficial effects in individuals with prolonged fatigue. In another study, four-week treatment of individuals with chronic fatigue with regulational effect for the blood cell and biochemical value listed for the evaluation of life related disease [11]-[17]. Fatigue is accompanied by various physical and psychological symptoms, including depression and sleep impairment. In the present study, fermented herbal decoction treatment also produced improvements in sleep quality; suggests that fermented herbal decoctions can also improve sleep problems that commonly accompany fatigue. 


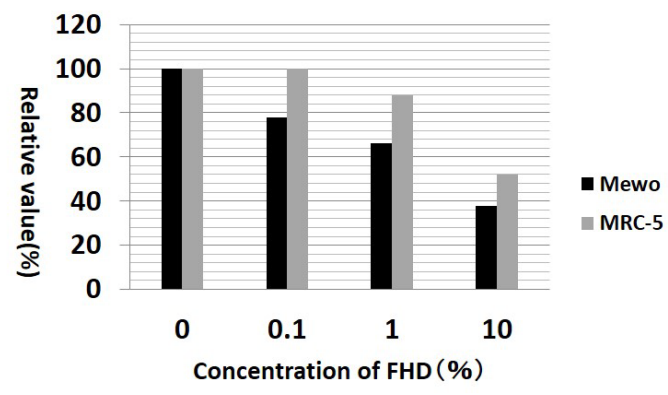

(a)

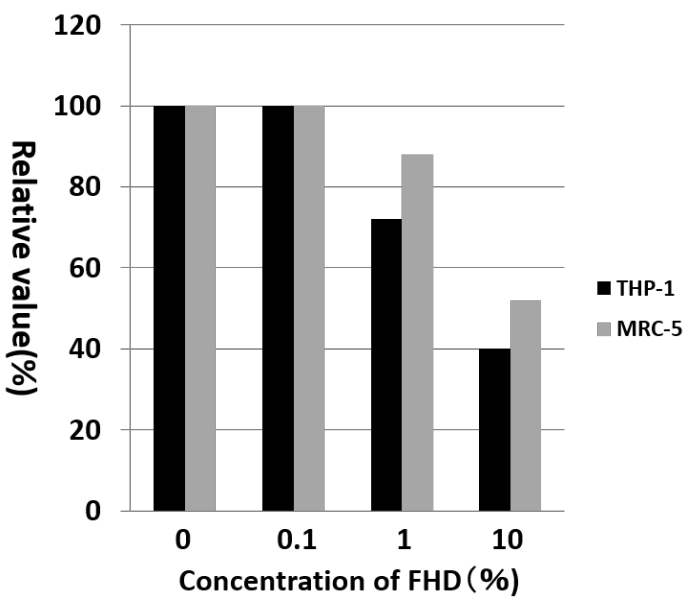

(b)

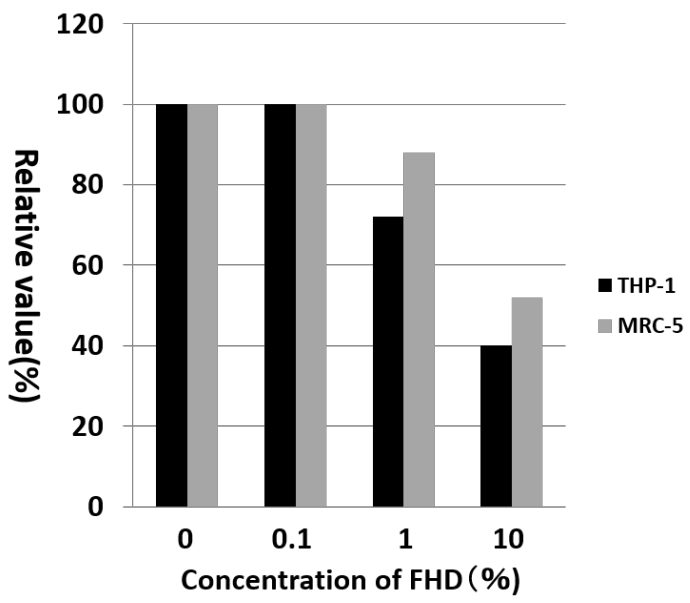

(c)

Figure 4. (a) Cytotoxic Effect for Human Malignant Melanoma Cell Line (Mewo) by FHD. An established human cell line were purchase from American Type Culture Collection (ATCC), A normal cell line and tumor cell line were prepared by ATCC. MRC-5; Human embryo fibroblast (Normal Cell Line). First, FHD was diluted and prepared $10 \%, 1 \%$ and $0.1 \%$ as final concentration in RPMI-1640 plus FCS. Then each cell line were prepared $5 \times 10^{4}$ cell in each microplate well. The plate were incubated with $\mathrm{CO}_{2}$ incubator. After $24 \mathrm{hrs}$ incubation cultured cell were washed with $1 \mathrm{ml}$ of PBS suspension. Trypan-blue dye (0.4\%) was mixed to indicate the living cell in the suspension as dye exclusion test; (b) Cytotoxic Effect for Human Leukemia Cell Line (THP-1) by FHD. An established human cell line were purchase from American Type Culture Collection (ATCC), A normal cell line and tumor cell line were prepared by ATCC, MRC-5; Human embryo fibroblast (Normal Cell Line). First, THP-1; Astrocytoma, was diluted and prepared $10 \%, 1 \%$ and $0.1 \%$ as final concentration in RPMI-1640 plus FCS. Then each cell line were prepared 5 X $10^{4}$ cell in each microplate well. The plate were incubated with $\mathrm{CO}_{2}$ incubator. After 24 hrs incubation cultured cell were washed with $1 \mathrm{ml}$ of PBS suspension. Trypan-blue dye (0.4\%) was mixed to indicate the living cell in the suspension as dye exclusion test; (c) Cytotoxic Effect for Human glioblastoma astrocytoma Cell Line (U373MG) by FHD. An established human cell line were purchase from American Type Culture Collection (ATCC), A normal cell line and tumor cell line were prepared by ATCC and U373MG; Human glioblastoma astrocytoma, MRC-5 ; Human embryo fibroblast (Normal Cell Line). First, FHD was diluted and prepared $10 \%, 1 \%$ and $0.1 \%$ as final concentration in RPMI- 1640 plus FCS. Then each cell line were prepared $5 \times 10^{4}$ cell in each microplate well. The plate were incubated with $\mathrm{CO}_{2}$ incubator. After 24 hrs incubation cultured cell were washed with 1 ml of PBS suspension. Trypan-blue dye (0.4\%) was mixed to indicate the living cell in the suspension as dye exclusion test

Additionally, improvements in sleep quality were still evident at four weeks after treatment completion, similar to the pattern observed for improvements in fatigue. Further, the ultimate objective of this study was to evaluate the other character of this decoction for cancer cell and pathogenic virus. Several reports describe CAMs as effective strategies for reducing fatigue. A systematic review of randomized controlled trials of various CAMs in patients with cancer and immunosuppressive virus diseases. However, this FHD could not showed the an- 
ti-bacterial activity, showing this FHD had a different mechanism of anti-bacterial chemotherapeutic agent such as antibiotics [14]. As for the cytotoxicity of FHD to malignant cancer cell line and pathogenic virus were eminent effect for especially for human tumor cell line. There are many finding were found in all over the world for anti-cancer agent, but almost all the material exhibited a toxicity both for cancer cell as well as normal cell. The natural product had been known for anti-fatigue agent but recently reported the anti-cancer effect elsewhere [51]-[78]. Finally, our fermented herbal decoction was obtained from 80 plant sources, such that there were numerous active components potentially mediating the observed efficacy. It will be useful in future studies to identify these active compounds and obtain pharmacokinetic data.

\section{Conclusion}

This study found that FHD for 4 weeks regulated a lymphocyte and granulocyte proportion. The fermented herbal decoction intervention also significantly improved anti-cancer cell line yet for normal cell line in vitro, which is a common wild herb ragweed. The more complete effect was showed for human cytomegalovirus.

\section{Conflict of Interest}

The authors declare that there is no conflict of interest regarding the publication of this paper.

\section{References}

[1] Miyazaki, S. (1977) Immunodificiency in Clinical Origin. Clinical Pediatrics, 1, 1001-1006.

[2] Kishida, K., Miyazaki, S., Take, H., Fujimoto, T., Shi, H., Sasaki, K. and Goya, N. (1978) Cranial Irradiation and Lymphocyte Subpopulation in Acute Lymphatic Leukemia. Journal of Pediatrics, 92, 785-786. https://doi.org/10.1016/S0022-3476(78)80155-3

[3] Yamaguchi, N., Takei, T., Chen, R., Hoxur, P. and Wu, H.W. (2013) Maternal Bias of Immunity to Her Offspring: Possibility of an Autoimmunity Twist out from Maternal Immunity to Her Young. Open Journal of Rheumatology and Autoimmune Diseases, 3, 40-54. https://doi.org/10.4236/ojra.2013.31008

[4] Murgita, R.A. and Tomasi Jr., T.B. (1975) Suppression of the Immune Response by Alpha-Fetoprotein. The Journal of Experimental Medicine, 141, 269-286. https://doi.org/10.1084/jem.141.2.269

[5] Paul, G., Margaret, S., Liew, Y.F. and Allan, M.M. (1995) CD4+ but Not CD8+ T Cells Are Required for the Induction of Oral Tolerance. International Immunology, 7, 501-504.

[6] Koshimo, H., Miyazawa, Y., Shimizu, Y. and Yamaguchi, N. (1989) Maternal Antigenic Stimulation Actively Produces Suppressor Activity in Offspring. Developmental \& Comparative Immunology, 13, 79-85. https://doi.org/10.1016/0145-305X(89)90020-7

[7] Zoeller, M. (1988) Tolerization during Pregnancy: Impact on the Development of 
Antigen-Specific Help and Suppression. European Journal of Immunology, 18, 1937-1943. https://doi.org/10.1002/eji.1830181211

[8] Auerback, R. and Clark, S. (1975) Immunological Tolerance: Transmission from Mother to Offspring. Science, 189, 811-813. https://doi.org/10.1126/science.1162355

[9] Shinka, S., Dohi, Y., Komatsu, T., Natarajan, R. and Amano, T. (1974) Immunological Unresponsiveness in Mice. I. Immunological Unresponsiveness Induced in Embryonic Mice by Maternofetal Transfer of Human-Globulin. Biken Journal, 17, 59-72.

[10] Aase, J.M., Noren, G.R., Reddy, D.V. and Geme Jr., J.W. (1972) Mumps-Virus Infection in Pregnant Women and the Immunologic Response of Their Offspring. The New England Journal of Medicine, 286, 1379-1382.

https://doi.org/10.1056/NEJM197206292862603

[11] Yamaguchi, N., Ueyama, T., Amat, N., Yimit, D., Hoxur, P., Sakamoto, D., Katoh, Y., Watanabe, I. and Su, S.Y. (2015) Bi-Directional Regulation by Chinese Herbal Formulae to Host and for Multi-Drug Resistant Staphylococcus aureus in Humans and Rodents. Open Journal of Immunology, 4, 18-32.

https://doi.org/10.4236/oji.2015.51003

[12] Takagi, A., Matsuzaki, T., Sato, M., Nomoto, K., Morotomi, M. and Yokokura, T. (1999) Inhibitory Effect of Oral Administration of Lactobacillus casei on 3-Methylcholanthrene-Induced Carcinogenesis in Mice. Medical Microbiology and Immunology, 188, 111-116. https://doi.org/10.1007/s004300050112

[13] Wang, X.X., Katoh, S. and Liu, B.X. (1998) Effect of Physical Exercise on Leukocyte and Lymphocyte Subpopulations in Human Peripheral Blood. Cytometry Research, 8, 53-61.

[14] Kitada, Y., Wan, W., Matsui, K., Shimizu, S. and Yamaguchi, N. (2000) Regulation of Peripheral White Blood Cells in Numbers and Functions through Hot-Spring Bathing during a Short Term Studies in Control Experiments. Journal of Japanese Society Balneology Climatology Physiological Medicine, 63, 151-164.

[15] Yamaguchi, N., Takahashi, T., Sugita, T., Ichikawa, K., Sakaihara, S., Kanda, T., Arai, M. and Kawakita, K. (2007) Acupuncture Regulates Leukocyte Subpopulations in Human Peripheral Blood. Evidence-Based Complementary and Alternative Medicine, 4, 447-453. https://doi.org/10.1093/ecam/nel107

[16] Eguchi, Y., Yamaguchi, N., Amat, N., Yimit, D., Hoxur, P. and Yokokawa, K. (2015) A New Activated Water Charged by Electrophoresis, Effect on the Experimentally Immuno-Suppressed Animal and Their Anti-Oxidative Activity. Open Journal of Immunology, 5, 122-132. https://doi.org/10.4236/oji.2015.53012

[17] Yamaguchi, N., Mastuba, Y., Okamoto, K., Sakamoto, D., Ueyama, T., Matsuno, H. and Amat, N. (2017) Lactobacilli Enjoyed Fermented Herbs on to the Last Fragment and Regulated Leucocyte Subsets and Anti-Oxidative Activity. Open Journal of Rheumatology and Autoimmune Diseases, 7, 30-45. https://doi.org/10.4236/ojra.2017.71003

[18] Gorantla, S., Dou, H., Boska, M., Destache, C.J., Nelson, J., Poluektova, L., Rabinow, B.E., Gendelman, H.E. and Mosley, R.L. (2006) Quantitative Magnetic Resonance and SPECT Imaging for Macrophage Tissue Migration and Nanofor-Mulated Drug Delivery. Journal of Leukocyte Biology, 80, 1165-1174. https://doi.org/10.1189/jlb.0206110

[19] Stoika, R.S., Lutsik, M.D., Barska, M.L., Tsyrulnyk, A.A. and Kashchak, N.I. (2002) In Vitro Studies of Activation of Phagocytic Cells by Bioactive Peptides. Journal of Physiology and Pharmacology, 53, 675-688. 
[20] Elbim, C., Pillet, S., Prevost, M.H., Preir, A., Girard, P.M., Rogine, N., Hakim, J., Israel, N. and Gougerot-Pocidalo, M.A. (2001) The Role of Phagocytes in HIV-Related Oxidative Stress. Journal of Clinical Virology, 20, 99-109. https://doi.org/10.1016/S1386-6532(00)00133-5

[21] Speer, C.P., Gahr, M. and Pabst, M.J. (1986) Phagocytosis Associated Oxidative Metabolism in Human Milk Macrophages. Acta Paediatrica, 75, 444-445. https://doi.org/10.1111/j.1651-2227.1986.tb10228.x

[22] Yamaguchi, N., Kawada, N., Jia, X., Okamoto, K., Okuzumi, K., Chen, R. and Takahashi, T. (2015) Overall Estimation of Anti-Oxidant Activity by Mammal Macrophage. Open Journal of Immunology, 5, 133-146.

[23] Al-Wadei, M.H., Al-Wadei, H.A. and Schuller, H.M. (2012) Pancreatic Cancer Cells and Normal Pancreatic Duct Epithelial Cells Express an Autocrine Catecholamine Loop That Is Activated by Nicotinic Acetylcholine Receptors a3, a5, and a7. Molecular Cancer Research, 10, 239-249. https://doi.org/10.1158/1541-7786.MCR-11-0332

[24] Abo, T., Kawate, T., Itoh, K. and Kumagai, K. (1981) Studies on the Bioperiodicity of the Immune Response. 1. Circadian Rhythms of Human T, B and K Cell Traffic in the Peripheral Blood. Journal of Immunology, 126, 1360-1363.

[25] Abo, T. and Kumagai, T. (1978) Studies of Surface Immunoglobulins on Human B Lymphocytes. III. Physiological Variations of SIg+ Cells in Peripheral Blood. Clinical \& Experimental Immunology, 33, 441-452.

[26] Suzuki, S., Toyabe, S., Moroda, T., Tada, T., Tsukahara, A. and Iiai, T. (1997) Circadian Rhythm of Leukocytes and Lymphocytes Subsets and Its Possible Correlation with the Function of the Autonomic Nervous System. Clinical \& Experimental Immunology, 110, 500-508. https://doi.org/10.1046/j.1365-2249.1997.4411460.x

[27] Schuller, H.M. (1989) Cell Type Specific, Receptor-Mediated Modulation of Growth Kinetics in Human Lung Cancer Cell Lines by Nicotine and Tobacco-Related Nitrosamines. Biochemical Pharmacology, 38, 3439-3442. https://doi.org/10.1016/0006-2952(89)90112-3

[28] LaMont, J.T. and O'Goman, T.A. (1978) Experimental Colon Cancer. Gastroenterology, 75, 1157-1169.

[29] Wong, H.P., Yu, L., Lam, E.K., Tai, E.K., Wu, W.K. and Cho, C.H. (2007) Nicotine Promotes Cell Proliferation via a7-Nicotinic Acetylcholine Receptor and Catecholamine-Synthesizing Enzymes-Mediated Pathway in Human Colon Adenocarcinoma HT-29 Cells. Toxicology and Applied Pharmacology, 221, 261-267. https://doi.org/10.1016/j.taap.2007.04.002

[30] McMillan, D.C., Forrest, L.M., O’Gorman, P., Angerson, W.J. and McArdle, C.S. (2002) Performance Status of Male and Female Advanced Cancer Patients Is Independently Predicted by Mid-Upper Arm Circumference Measurement. Nutrition and Cancer, 2, 191-193. https://doi.org/10.1207/S15327914NC422_7

[31] Arredondo, J., Chernyavsky, A.I. and Grando, S.A. (2006) Nicotinic Receptors Mediate Tumorigenic Action of Tobacco-Derived Nitrosamines on Immortalized Oral Epithelial Cells. Cancer Biology \& Therapy, 5, 511-517. https://doi.org/10.4161/cbt.5.5.2601

[32] Hsu, C.Y., Lee, Y.H. and Hsia, C.Y. (2013) Performance Status Enhances the Selection of Treatment for Patients with Hepatocellular Carcinoma within the Milan Criteria. Annals of Surgical Oncology, 6, 2035-2042. https://doi.org/10.1245/s10434-012-2847-8

[33] Al-Wadei, M.H., Al-Wadei, H.A. and Schuller, H.M. (2012) Effects of Chronic Ni- 
cotine on the Autocrine Regulation of Pancreatic Cancer Cells and Pancreatic Duct Epithelial Cells by Stimulatory and Inhibitory Neurotransmitters. Carcinogenesis, 33, 1745-1753. https://doi.org/10.1093/carcin/bgs229

[34] Murayama, T., Kuno, K., Jisaki, F., Obuchi, M., Sakamuro, D., Furukawa, T., Mukaida, N., Matsushima, K, (1994) Enhancement of Human Cytomegalovirus Replication in a Human Lung Fibroblast Cell Line by Interleukin-8. Journal of Virology, 68, 7582-7585.

[35] Jacobs, B.B., Jones, C.M. and Belle, J.P. (1970) Characteristics of a Diploid Cell Designated MRC-5. Nature, 227, 168-173. https://doi.org/10.1038/227168a0

[36] Takahashi, T., Sumino, H., Kanda, K. and Yamaguchi, N. (2009) Acupuncture Modifies Immune Cells. Journal of Experimental \& Clinical Medicine, 1, 17-22. https://doi.org/10.1016/S1878-3317(09)60006-1

[37] Kasai, H., Horiuchi, I., Yamaguchi, N. and Ito, K. (2004) IL-12 Production Induced by Agaricus blazei Fraction H(ABH) Involves Toll-like Receptor (TLR). eCAM, 1, 259-267.

[38] Penman, D., El-Omar, E., McGregor, J.R., Hillan, K.J., O’Dwyer, P. and McColl, K.E. (1993) Omeprazole Inhibits Colorectal Carcinogenesis Induced by Azoxymethane in Rats. Gut, 34, 1559-1565. https://doi.org/10.1136/gut.34.11.1559

[39] Maisel, A.S., Harris, T., Rearden, C.A. and Michel, M.C. (1990) Beta-Adrenergic Receptors in Lymphocyte Subsets after Exercise. Alterations in Normal Individuals and Patients with Congestive Heart Failure. Circulation, 82, 2003-2010.

[40] Cramer, D.V., Kunz, H.W. and Gill III, T.J. (1974) Immunologic Sensitization Prior to Birth. American Journal of Obstetrics \& Gynecology, 120, 431-439. https://doi.org/10.1016/0002-9378(74)90248-8

[41] Furukawa, T., Fioretti, A. and Plotkin, S. (1973) Growth Characteristics of Cytomegalovirus in Human Fibroblasts with Demonstration of Protein Synthesis Early Viral Replication. Journal of Virology, 11, 991-997.

[42] Yamaguchi, N., Akazawa-Kudoh, S., Sawada, M., Fujimoto, Y. and Murayama, T. (2017) Fermented Medicinal Plant Designed by Lactobacillus Hits Alternative Complement Pathway and Controlled hA1c Level. Natural Products Chemistry and Research, 5, 3.

[43] Wentworth, B.B. and French, L. (1970) Plaque Assay of Cytomegalovirus Strain of Human Origin. Experimental Biology and Medicine, 135, 253-258. https://doi.org/10.3181/00379727-135-35031

[44] Furukawa, T., Jisaki, F., Sakamuro, D., Takegami, T. and Murayama, T. (1994) Detection of Human Cytomegalovirus Genome in Uterus Tissue. Archives of Virology, 135, 265-277. https://doi.org/10.1007/BF01310013

[45] Harada, K., Eizuru, Y., Isashiki, Y., Ihara, S. and Minamishima, Y. (1997) Genetic Analysis of a Clinical Isolate of Human Cytomegalovirus Exhibiting Resistance Against Both Ganciclovir and Cidofovir. Archives of Virology, 142, 215-225. https://doi.org/10.1007/s007050050072

[46] Chomczynski, P. and Sacchi, N. (1987) Single Step Method of RNA Isolation by Acid Guanidium Thiocyanate-Phenol-Chloroform Extraction. Analytical Biochemistry, 162, 156-159. https://doi.org/10.1016/0003-2697(87)90021-2

[47] Jorgensen, E.C.B., and Autrup, H. (1996) Autoregulation of Human CYP1A1 Gene Promotor Activity in HepG2 and MCF-7 Cells. Carcinogenesis, 17, 435-441. https://doi.org/10.1093/carcin/17.3.435

[48] Nasser, M.I., Masood, M., Wei, W., Li, X., Zhou, Y., Liu, B., Li, J. and Li, X. (2017) 
Cordycepin Induces Apoptosis in SGC-7901 Cells through Mitochondrial Extrinsic Phosphorylation of PI3K/Akt by Generating ROS. International Journal of Oncology, 50, 911-919. https://doi.org/10.3892/ijo.2017.3862

[49] Yamaguchi, N., Wan, W.H., Sakamoto, D., Nurmuhammad, N., Matsumoto, K., Takei T., Okuzumi, K., Murayama, Y. and Takahashi, T. (2013) Regulative Effect for Natural Killer Cell by Hot Spring Hydrotherapy-Quantitative and Qualitative Discussion. Open Journal of Immunology, 3, 201-209. https://doi.org/10.4236/oji.2013.34025

[50] Yu, X., Ling, J., Liu, X., Guo, S., Lin, Y., Liu, X. and Su, L. (2017) Cordycepin Induces Autophagy-Mediated c-FLIPL Degradation and Leads to Apoptosis in $\mathrm{Hu}$ man Non-Small Cell Lung Cancer Cells. Oncotarget, 24, 6691-6699.

[51] Choi, Y.H., Kim, G.Y. and Lee, H.H. (2014) Anti-Inflammatory Effects of Cordycepin in Lipopolysaccharide-Stimulated RAW 264.7 Macrophages through Toll-Like Receptor 4-Mediated Suppression of Mitogen-Activated Protein Kinases and NF- $\kappa$ B Signaling Pathways. Drug Design, Development and Therapy, 8, 1941-1953. https://doi.org/10.2147/DDDT.S71957

[52] Jang, K.J., Kwon, G.S., Jeong, J.W., Kim, C.H., Yoon, H.M., Kim, G.Y., Shim, J.H., Moon, S.K., Kim, W.J. and Choi, Y.H. (2015) Cordyceptin Induces Apoptosis through Repressing hTERT Expression and Inducing Extranuclear Export of hTERT. Journal of Bioscience and Bioengineering, 119, 351-357. https://doi.org/10.1016/j.jbiosc.2014.08.008

[53] Chen, Y., Yang, S.H., Hueng, D.Y., Syu, J.P., Liao, C.C. and Wu, Y.C. (2014) Cordycepin Induces Apoptosis of C6 Glioma Cells through the Adenosine 2A Receptor-p53-Caspase-7-PARP Pathway. Chemico-Biological Interactions, 216, 17-25. https://doi.org/10.1016/j.cbi.2014.03.010

[54] Sato, A., Yoshikawa, N., Kubo, E., Kakuda, M., Nishiuchi, A., Kimoto, Y., Takahashi, Y., Kagota, S., Shinozuka, K. and Nakamura, K. (2013) Inhibitory Effect of Cordycepin on Experimental Hepatic Metastasis of B16-F0 Mouse Melanoma Cells. In Vivo, 27, 729-732.

[55] Tuli, H.S., Sharma, A.K., Sandhu, S.S. and Kashyap, D. (2013) Cordycepin: A Bioactive Metabolite with Therapeutic Potential. Life Sciences, 93, 863-869.

https://doi.org/10.1016/j.lfs.2013.09.030

[56] Lee, H.H., Jeong, J.W., Lee, J.H., Kim, G.Y., Cheong, J., Jeong, Y.K., Yoo, Y.H. and Choi, Y.H. (2013) Cordycepin Increases Sensitivity of Hep3b Human Hepatocellular Carcinoma Cells to TRAIL-Mediated Apoptosis by Inactivating the JNK Signaling Pathway. Oncology Reports, 30, 1257-1264.

https://doi.org/10.3892/or.2013.2589

[57] Lee, H.H., Park, C., Jeong, J.W., Kim, M.J., Seo, M.J., Kang, B.W., Park, J.U., Kim, G.Y., Choi, B.T., Choi, Y.H. and Jeong, Y.K. (2013) Apoptosis Induction of Human Prostate Carcinoma Cells by Cordycepin through Reactive Oxygen Species-Mediated Mitochondrial Death Pathway. International Journal of Oncology, 42, 1036-1044.

[58] Kadomatsu, M., Nakajima, S., Kato, H., Gu, L., Chi, Y., Yao, J. and Kitamura, M. (2012) Cordycepin as a Sensitizer to Tumour Necrosis Factor (TNF)- $\alpha$-Induced Apoptosis through Eukaryotic Translation Initiation Factor $2 \alpha$ (eIF2 $\alpha$ )- and Mammalian Target of Rapamycin Complex 1 (mTORC1)-Mediated Inhibition of Nuclear Factor (NF)-кB. Clinical \& Experimental Immunology, 168, 325-332. https://doi.org/10.1111/j.1365-2249.2012.04580.x

[59] Jeong, J.W., Jin, C.Y., Park, C., Han, M.H., Kim, G.Y., Moon, S.K., Kim, C.G., 
Jeong, Y.K., Kim, W.J., Lee, J.D. and Choi, Y.H. (2012) Inhibition of Migration and Invasion of LNCaP Human Prostate Carcinoma Cells by Cordycepin through Inactivation of Akt. International Journal of Oncology, 40, 1697-1704.

[60] Choi, S., Lim, M.H., Kim, K.M., Jeon, B.H., Song, W.O. and Kim, T.W. (2011) Cordycepin-Induced Apoptosis and Autophagy in Breast Cancer Cells Are Independent of the Estrogen Receptor. Toxicology and Applied Pharmacology, 257, 165-173. https://doi.org/10.1016/j.taap.2011.08.030

[61] Jeong, J.W., Jin, C.Y., Park, C., Hong, S.H., Kim, G.Y., Jeong, Y.K., Lee, J.D., Yoo, Y.H. and Choi, Y.H. (2011) Induction of Apoptosis by Cordycepin via Reactive Oxygen Species Generation in Human Leukemia Cells. Toxicology In Vitro, 25, 817-824. https://doi.org/10.1016/j.tiv.2011.02.001

[62] Lee, S.J., Kim, S.K., Choi, W.S., Kim, W.J. and Moon, S.K. (2009) Cordycepin Causes p21WAF1-Mediated G2/M Cell-Cycle Arrest by Regulating c-Jun N-Terminal Kinase Activation in Human Bladder Cancer Cells. Archives of Biochemistry and Biophysics, 490, 103-109. https://doi.org/10.1016/j.abb.2009.09.001

[63] Cho, H.J., Cho, J.Y., Rhee, M.H., Kim, H.S., Lee, H.S. and Park, H.J. (2007) Inhibitory Effects of Cordycepin (3'-Deoxyadenosine) a Component of Cordyceps Militaris, on Human Platelet Aggregation Induced by Thapsigargin. Journal of Microbiology and Biotechnology, 17, 1134-1138.

[64] Lui, J.C., Wong, J.W., Suen, Y.K., Kwok, T.T., Fung, K.P. and Kong, S.K. (2007) Cordycepin Induced Eryptosis in Mouse Erythrocytes through a $\mathrm{Ca}^{2+}$-Dependent Pathway without Caspase-3 Activation. Archives of Toxicology, 81, 859-865. https://doi.org/10.1007/s00204-007-0214-5

[65] Cho, H.J., Cho, J.Y., Rhee, M.H., Lim, C.R. and Park, H.J. (2006) Cordycepin (3'-Deoxyadenosine) Inhibits Human Platelet Aggregation Induced by U46619, a $\mathrm{TXA}_{2}$ Analogue. Journal of Pharmacy and Pharmacology, 58, 1677-1682. https://doi.org/10.1211/jpp.58.12.0016

[66] Wu, W.C., Hsiao, J.R., Lian, Y.Y., Lin, C.Y. and Huang, B.M. (2007) The Apoptotic Effect of Cordycepin on Human OEC-M1 Oral Cancer Cell Line. Cancer Chemotherapy and Pharmacology, 60, 103-111. https://doi.org/10.1007/s00280-006-0354-y

[67] Wu, J.Y., Zhang, Q.X. and Leung, P.H. (2007) Inhibitory Effects of Ethyl Acetate Extract of Cordyceps sinensis Mycelium on Various Cancer Cells in Culture and B16 Melanoma in C57BL/6 Mice. Phytomedicine, 14, 43-49. https://doi.org/10.1016/j.phymed.2005.11.005

[68] Ng, T.B. and Wang, H.X. (2005) Pharmacological Actions of Cordyceps, a Prized Folk Medicine. Journal of Pharmacy and Pharmacology, 57, 1509-1519. https://doi.org/10.1211/jpp.57.12.0001

[69] Wang, B.J., Won, S.J., Yu, Z.R. and Su, C.L. (2005) Free Radical Scavenging and Apoptotic Effects of Cordyceps sinensis Fractionated by Supercritical Carbon Dioxide. Food and Chemical Toxicology, 43, 543-552. https://doi.org/10.1016/j.fct.2004.12.008

[70] Maebuchi, M., Yamaguchi, N. and Furuy, S. (2011) Soy Peptide as Functional Food Component. Medicine and Biology, 155, 566-576,

[71] Wan, W., Shimizu, S., Ikawa, H., Sugiyama, K. and Yamaguchi, N. (2002) Maternal Cell Traffic Bounds for Immune Modulation: Tracking Maternal H-2 Alleles in Spleen of Baby Mice by DNA Fingerprinting. Immunology, 107, 261-267. https://doi.org/10.1046/j.1365-2567.2002.01499.x

[72] Mastuba, Y., Okamoto, K., Kato, Y., Yamaguchi, N. and Akazawa-Kudoh, S. (2017) Fermented Ethnic Medicine (Pueraria mirifica) Designed by Lactobacillus Regu- 
lated Leukocyte Subsets via Activation of Complement Components. Open Journal of Rheumatology and Autoimmune Diseases, 7, 65-79. https://doi.org/10.4236/ojra.2017.71006

[73] Kubota, H., Amat, N., Yimit, D., Hoxur, P. and Yamaguchi, N. (2015) Single Cellular Algae Digestive Supplement Designed by Yeast \& Lactobacillus Rearranged Leukocyte Subsets through Activation of Complement Components. Open Journal of Immunology, 5, 104-121.

[74] Watanabe, Y., Yamaguchi, N., Horiuch, I. and Murayama, T. (2015) Fermented Black Turmeric Designed by Lactobacillus Rearranged Leukocyte Subsets and Anti-Oxidative Activity. Open Journal of Immunology, 5, 199-214. https://doi.org/10.4236/oji.2015.53016

[75] Yamaguchi, N., Matsuba, K., Okamoto, K., Ueyama, T., Matsuba, Y., Okuzumi, K., Watanabe, I. and Takahashi, T. (2013) Rodent Macrophage Select Vin Blank Together with Vin Rouge According to SO Level In Situ. Open Journal of Rheumatology and Autoimmune Diseases, 4, 240-247. https://doi.org/10.4236/ojra.2014.44033

[76] Yamaguchi, N., Keiko Matsuba, K., Okamoto, K., Takanao Ueyama, T., Matsuba, Y., Okuzumi, K., Watanabe, I. and Takahashi, T. (2014) Rodent Macrophage Select Vin Blank Together with Vin Rouge According to SO Level In Situ. Open Journal of Rheumatology and Autoimmune Diseases, 4, 240-247.

https://doi.org/10.4236/ojra.2014.44033

[77] Yamaguchi, N., Arai, M. and Murayama, T. (2015) Aspect of QOL Assessment and Proposed New Scale for Evaluation. Open Journal of Immunology, 5, 147-182. https://doi.org/10.4236/oji.2015.53014

[78] Maneckjee, R. and Minna, J.D. (1990) Opioid and Nicotine Receptors Affect Growth Regulation of Human Lung Cancer Cell Lines. Proceedings of the National Academy of Sciences, 87, 3294-3298. https://doi.org/10.1073/pnas.87.9.3294 